\title{
Animal Models for SARS-CoV-2 research: Systematic Review of Literature and Future Directions
}

\author{
Kabita Pandey ${ }^{1}$, Arpan Acharya ${ }^{1}$, Mahesh Mohan ${ }^{2}$, Caroline $\mathrm{Ng}^{1}$, Patrick Reid ${ }^{1}$, and \\ Siddappa Byrareddy ${ }^{3}$ \\ ${ }^{1}$ University of Nebraska Medical Center \\ ${ }^{2}$ Texas Biomedical Research Institute \\ ${ }^{3}$ University of Nebraska Medical Center Department of Pharmacology and Experimental \\ Neuroscience
}

June 22, 2020

\begin{abstract}
Emerging and reemerging viral diseases can lead to devastating effects on human lives and at times also lead to economic crises. The ongoing COVID-19 pandemic due to the novel coronavirus (nCoV), severe acute respiratory syndrome coronavirus 2 (SARS-CoV-2), which originated in Wuhan, China, has caused a global public health emergency. Still, the molecular mechanism of transmission of SARS-CoV-2, its clinical manifestations and pathogenesis is not completely understood. The global scientific community has intensified their efforts to understand the biology of SARS-CoV-2 to develop vaccines and therapeutic interventions to prevent the rapid spread of the virus and to control mortality and morbidity associated with COVID-19. To understand the pathophysiology of SARS-CoV-2, appropriate animal models that mimic the biology of human SARS-COV-2 infection is urgently needed. In this review, we outline animal models that have been used to study previous human coronaviruses ( $\mathrm{HCoVs}$ ), that includes severe acute respiratory syndrome coronavirus (SARS-CoV) and Middle East respiratory syndrome coronavirus (MERS-CoV). Importantly, we discuss which model is appropriate for SARS-CoV-2 as well as the advantages and disadvantages of each.
\end{abstract}

\section{Introduction}

In late December 2019, a viral outbreak of unknown etiology in Wuhan, China was reported in which several patients were admitted to hospitals with a diagnoses of pneumonia and respiratory distress (Bogoch et al., 2020). This "viral pneumonia" was found to be linked to the Huanan Seafood Market in Wuhan, China (Huang et al., 2020). This emerging novel coronavirus (nCoV), was named SARS-CoV-2, and on February 11, 2020 the WHO named the disease associated with SARS-CoV-2 Corona virus disease 19 (COVID-19) (Q. Li et al., 2020; Rothan \& Byrareddy, 2020). Similar to previously detected HCoVs, such as SARS-CoV and MERS-CoV, this virus is known to infect people and spread rapidly from person-to-person through droplets (Lewis, 2020). The COVID-19 outbreak was recognized as a pandemic on March 11, 2020 (Cucinotta \& Vanelli, 2020). As of May 29, 2020, the virus has surpassed 5,888,498 infections and 363,210 deaths worldwide. At the same time, in the United States of America there are 1,743,235 confirmed cases and 102,516 deaths. (https://coronavirus.jhu.edu/us-map)

CoVs are enveloped and positive-stranded RNA viruses that have large viral genomes ranging from 26- 32 $\mathrm{kb}$ in length (Denison, Graham, Donaldson, Eckerle, \& Baric, 2011). Common HCoVs such as 229E and NL63 belong to alpha coronavirus genus, while comparatively OC43 and HKU1 belong to the genus betacoronavirus, which can cause mild and self-limiting respiratory tract infections (Corman, Muth, Niemeyer, \& Drosten, 2018). In the last two decades, the pandemics associated with SARS-CoV and MERS-CoV, be- 
tacoronaviruses, cause Severe Acute Respiratory Syndrome (SARS) and Middle East Respiratory Syndrome (MERS) respectively $(11,12)$. The antigenicity of the virus depends on the enveloped spike protein, which is the major determinant of attachment and entry of the virus into host cells (Sui et al., 2004). The viruses belonging to the family Coronaviridae have a wide variety of hosts including: birds, pigs, cats, dogs, bats, pangolins, and humans (Woo et al., 2012). These beta coronaviruses have resulted in symptoms of varying severity ranging from comparative symptoms of common cold affecting the upper respiratory tract (URT), to more severe symptoms of bronchitis, pneumonia, and associated fatalities affecting the lower respiratory tract (LRT) (Peiris et al., 2003; Raj, Osterhaus, Fouchier, \& Haagmans, 2014). The outbreak of SARS pandemic in 2002 resulted in a $9.6 \%$ fatality rate from 8096 cases and almost 774 fatalities worldwide. ("World Health Organization. Geneva (Switzerland): World Health Organization; 2003. Summary of probable SARS cases with onset of illness from 1 November 2002 to 31 July 2003 "). MERS which emerged in 2012 and observed for new cases until October 2018, had 2229 confirmed cases and 791 deaths for a higher rate of fatality near 35.5\% ("World Health Organization . Geneva (Switzerland): World Health Organization; 2019. MERS situation update, December 2019,"). These viruses are known for being cross-species (zoonotic) and humanto-human communicable from where transmission can be coupled with severe pathological effects (Corman et al., 2018). SARS-CoV and MERS-CoV use Angiotensin-Converting Enzyme 2 (ACE2) (W. Li et al., 2003) and Dipeptidyl peptidase 4 (DPP-4) (Raj et al., 2013) as receptors to enter host cells, respectively.

SARS-CoV-2 belongs to the same clade of beta coronaviruses as SARS-CoV and MERS-CoV, with more than $80 \%$ and $50 \%$ sequence similarity, respectively (Cui, Li, \& Shi, 2019). The genome of SARS-CoV-2, which was isolated from a cluster of patients with pneumonia in Wuhan, had more than $90 \%$ nucleotide identity with the bat CoV, RaTG13 (Zhou et al., 2020). The exact route of animal-to-human transmission of SARS-CoV-2 is still unclear but genomic data suggest their evolution is from bats to humans (Zhou et al., 2020) (Figure 1 ). Recent study suggested that 99\% sequence similarity of SARS-CoV-2 structural proteins with coronavirus isolated from pangolins suggesting pangolins as intermediate hosts (Xiao et al., 2020) (Figure 1 ). Another study suggested that snakes could be an intermediate host for SARS-CoV-2 based on codon usage (Ji, Wang, Zhao, Zai, \& Li, 2020) (Figure 1 ). In contrast, the bamboo rat has also been proposed to be the intermediate host (Nanshan, 2020) (Figure 1 ). Despite active investigation, the definitive animal reservoir responsible for cross-species transmission of SARS-CoV-2 from animals to humans remains elusive (Bassetti, Vena, \& Giacobbe, 2020). Like SARS and MERS, clinical symptoms of COVID-19 range from acute to severe. Characteristic mild symptoms include fever, sore throat with a dry cough, respiratory stress, and myalgia (Huang et al., 2020). In severe conditions, bilateral lung ground-glass opacity is observed under chest-computed tomography. (Acharya, Kevadiya, Gendelman, \& Byrareddy, 2020; H. Shi et al., 2020). Neurological manifestations like dizziness, headache, ataxia, seizure with taste, smell and visual impairment were reported (Mao et al., 2020) Histopathological reports showed diffuse alveolar damage and pulmonary edema, indicating acute respiratory distress syndrome (Rothan \& Byrareddy, 2020; $\mathrm{Xu}$ et al., 2020), which was also seen in SARS-CoV infection (Nicholls et al., 2003).

SARS-CoV-2 uses ACE2 as a receptor for binding and entering host cells, which is facilitated by the host protease Transmembrane Serine Protease 2 (TMPRSS2) (Hoffmann et al., 2020). ACE2 is expressed in airway epithelial cells, lung parenchyma, and vascular endothelial cells in the kidney and small intestine (Hamming et al., 2004). Therapeutic interventions for COVID-19 such as vaccines, antivirals, antibodies, etc are an active area of investigation (Mukherjee, 2020) and several are already in clinical trials (Scavone et al., 2020). In-vitro cell models and organoids are also helpful to understand the virus entry, life cycle and testing the efficacy of therapeutics (Takayama, 2020) but they are unable to exhibit the exact pathological changes and lesions that are specific to particular organs. Therefore, suitable biological relevant animal models are necessary for testing the safety and efficacy of the vaccines, antivirals and other potential therapeutics that are currently in the pipeline.

\section{Requirements of a SARS-CoV-2 animal model}

A perfect animal model should be permissive to infection and be able to mimic the clinical pathology of disease as observed in humans (Sutton \& Subbarao, 2015). These models play a crucial role in studying host- 
virus interactions that contribute to disease pathogenesis and transmission. A protocol for the development of animal models is mentioned by the 'FDA animal efficacy rule'(Product Development Under the Animal Rule, 2015). Accordingly, these models should have the same receptors as those present in humans that help viruses in the attachment and entry process, and the outcome of the infection should be as severe as in humans. In many emerging disease studies, in vitro studies cannot completely simulate human pathophysiology. Also, the immunological components are very complex in humans, which cannot be proven in the in-vitro experiments. However, despite the differences in animal model translation to humans, a lot of critical information related to the pathogenesis, prevention and treatment of newly emerging infectious diseases can still be discovered.

Animal models can be categorized as small or large. Small animal models include the use of mice, rats, ferrets, hamsters and rabbits, which are relatively smaller in size and require limited space. Small animal models offer several advantages because the animals and reagents specific to the animals are easily available, the animals can be handled with less effort and cost, and allows the use of a large number of animals to provide data for strong statistical analyses (Sutton \& Subbarao, 2015). The small animal model is limited by the significant intrinsic biological differences between humans and rodents or small mammals, which have led to the requirement that viruses must be adapted to the animals, or the animals, must be genetically manipulated to recapitulate the human system (Subbarao et al., 2004). In addition, the animals' short life span hampers the ability to monitor the long-term prognosis of the disease (Gretebeck \& Subbarao, 2015). Large animal models such as non-human primates (NHP) are more reliable models to replicate human disease pathogenesis as they are physiologically, immunologically and genetically more closely related to humans (Fujiyama et al., 2002; Lu et al., 2008). The major limitation of using NHP models are the high cost and resources involved in the study, which limits the number of animals that may be included in a study and thus adversely affecting the statistical power of the outcome. In addition, most NHPs are outbred animals and have a wide variability in genetic backgrounds, which sometimes make it difficult to interpret the outcome of a study due to variability in results among individual animals ( $\mathrm{Lu}$ et al., 2008).

For the ongoing COVID-19 pandemic, direct human clinical trials are complicated by the mild to severe forms of the disease due to genetic diversities, age of the host, comorbidities, multiple infections along with other preexisting diseases (P. K. Chan \& Chan, 2013; Gold et al., 2020; "What explains Covid-19's lethality for the elderly? Scientists look to 'twilight' of the immune system," 2020). The virus uses the ACE-2 receptor that is expressed in cells found in the heart, lungs, gastrointestinal tract, and renal tract (Hamming et al., 2004; Hoffmann et al., 2020). After entry, viral replication kinetics in most of the target cells remains unknown. Air droplets and aerosols are critical aspects of the global spread of SARS-CoV-2 (Hamid, Mir, \& Rohela, 2020; Meselson, 2020). Regardless, there is an urgent need to understand the risks factors of transmission for SARS-CoV-2 (Figure 2 ). The symptoms of COVID-19 with other specific and non-specific upper respiratory tract symptoms are similar in nature, which make it difficult to distinguish from other diseases (Bhatraju et al., 2020). A case report from Eiju General Hospital Tokyo, Japan, showed the existence of the Influenza virus along with SARS-CoV-2 showing similar types of symptoms that posed a difficulty in the differential diagnosis of the two diseases (Azekawa, Namkoong, Mitamura, Kawaoka, \& Saito, 2020). Another case in Rhode Island showed the co-infection of SARS-CoV-2 with Human metapneumovirus, where a patient tested positive for human metapneumovirus but failed to test for SARS-CoV-2. The symptoms did not subside even after treatment for metapneumovirus. Nevertheless, when the patient was tested for SARS-CoV-2 by PCR and the results came back as positive (Touzard-Romo, Tape, \& Lonks, 2020). A travel-related case of an 80-year old male from Japan, with a history of diabetes, showed coinfection of SARS-CoV-2 and Legionella with respiratory distress and gastrointestinal symptoms. The patient passed away after 13 days but was later confirmed to be infected with COVID-19 (Arashiro et al., 2020). These individual case reports compel the need for suitable animal studies of SARS-CoV-2 co-infection with other pathogens with similar disease manifestations for better clinical outcomes.

COVID-19 has a variety of clinical outcomes (J. F.-W. Chan et al., 2020; Huang et al., 2020). Most of the patients who are admitted to hospitals with severe clinical manifestations have other comorbid conditions such as diabetes, cardiovascular disease, gastrointestinal disease, or hypertension (Gold et al., 2020). In the case of Influenza, one publication showed that the risk of the Acute Respiratory Distress increases 3.4-fold 
in the H7N9 infected person with similar comorbidity (H. N. Gao et al., 2013). Age-related co-morbidity has mostly affected the transmission cycle of disease (Sun et al., 2020). The exact mechanism of how these comorbidities deteriorate SARS-CoV-2 patient conditions remains unknown. These comorbid conditions that lead to severe to fatal outcomes are another aspect of COVID-19 pathogenesis that needs a suitable animal model for study.

There is a concerted effort in the research community to develop therapeutics and vaccines against COVID19. For example, Remdesivir is an antiviral drug that failed the clinical trial for Ebola a decade ago (Mulangu et al., 2019) and now has been proposed for COVID-19 treatment (Beigel et al., 2020) (ClinicalTrials.gov: NCT04257656, NCT04252664, NCT04280705). It was repurposed for COVID-19 treatment because it directly blocked RNA synthesis (Agostini et al., 2018). Preliminary reports for Remdesivir in a clinical trial of 1063 adult patients with lower respiratory tract infection showed a shortening in recovery time in 538 patients given Remdesivir intravenously (median 11 days), compared to the 521 patients given a placebo (median 15 days) (Beigel et al., 2020). However, there were still serious adverse effects reported in COVID-19 patients given Remdesivir, but Remdesivir worked better in comparison to the placebo. To test the efficacy of Remdesivir in disease outcome, a rhesus macaque model of SARS-CoV-2 infection was developed, where infected macaques developed mild to moderate clinical symptoms(Brandi N. Williamson, 2020). The macaques treated with Remdesivir did not show any respiratory distress, and viral titers in bronchoalveolar lavage was reduced after 12 hours of treatment, suggesting that Remdesivir may have some beneficial effect in the treatment of COVID-19 (Brandi N. Williamson, 2020). A study using Lopinavir, a protease inhibitor and Ritonavir, that primes the action of Lopinavir widely used to treat HIV infection, are in clinical trials for COVID-19 (Bhatnagar et al., 2020). The combination of Lopinavir and Ritonavir had shown efficacy against SARS-CoV in mice (Chu et al., 2004) and MERS-CoV in NHPs (J. F. Chan et al., 2015). ACE-2 inhibitors as well as some fusion inhibitors such as Arbidol are also in clinical trials (Chinese Government Clinical Trials: ChiCTR2000029573)(Wang et al., 2020). Clinical trials using convalescent serum as treatment for COVID-19 has already begun at the Icahn School of Medicine at Mount Sinai, New York, USA (Sean T. H. Liu, 2020) . Similarly, polyclonal antibodies have also been employed in clinical trials because polyclonal human immunoglobulin G (IgG) had shown effectiveness against MERS-CoVs.(Luke et al., 2016). Vaccine development is important to the control of disease and protection against the transmission of the virus to immunized individuals. Many groups are working to develop potential vaccines for SARS-CoV-2, out of which some candidates are already in clinical trials (Mukherjee, 2020). Moderna, a vaccine manufacturer, has started phase II clinical trials of their vaccine candidate mRNA- 1273, which passed phase I trial recently by generating desired immune response by natural infection (ClinicalTrials.gov Identifier: NCT04283461) ("Moderna Moderna announces funding award from CEPI to accelerate development of messenger RNA (mRNA) vaccine against novel coronavirus; 2020. [accessed 2020 February15]

,"). A purified inactivated SARS-CoV-2 virus candidate (PiCoVacc) tested in mice, rats and non-human primates have also shown protective immune response suggesting neutralizing activity against SARS-CoV-2 (Q. Gao et al., 2020). Recombinant protein-based vaccines by University of Queensland and viral-vector based vaccines by University of Oxford, England are also being actively tested for vaccine efficacy ("Developing Therapeutics and Vaccines for Coronaviruses,"). Another study has suggested that polio vaccine could be used to prevent SARS-CoV-2 (Yeh et al., 2020).

In order to study various unanswered questions about the disease pathogenesis, suitable animal models are essential. Several studies are in progress to find suitable animal models to study the transmission, disease pathogenesis, and pre-clinical trials of potential therapeutics for the management of COVID-19. However, to successfully end the COVID-19 pandemic, efforts to develop vaccines to prevent the virus spread should synchronize with studies to uncover disease pathogenic mechanisms in comorbid and high-risk co-infection conditions. Although difficult, identifying a model that adequately mimics the human disease of SARSCoV-2 is bolstered by several studies of SARS-CoV and MERS-CoV, which has provided some preliminary insights on the models. All laboratory animal models, like mice to hamsters then ferret to NHP's, are equally valuable to dissect out various questions to better understand disease mechanisms. 


\section{Animal models feasible for SARS-CoV-2 studies:}

\subsection{Mouse Model:}

Mice are the most widely used animal models in infectious disease research. Many inbred mouse strains have been tested for SARS-CoV infections. BALB/c mice, C57BL/6 (B6) and 129SvEv mice were challenged intranasally with Urbani strain (Glass, Subbarao, Murphy, \& Murphy, 2004; Roberts et al., 2005). This resulted in a productive infection with peak titers on day 3 but there was an early clearance of the virus. Furthermore, mice did not lose weight, display signs of clinical disease, or develop pulmonary pathology that were observed in humans (Yin \& Wunderink, 2018). Mutant mice such as B6, Beige, and CD1-/- (lack NK cell function and NK-T cells) and RAG1 ${ }^{-/}$mice (lack T and B lymphocytes) did not develop clinical disease (Glass et al., 2004). STAT1/- mice showed some clinical signs of weight loss and bronchiolitis but were unable to show the pathological signs and mortality as observed in human cases (Frieman et al., 2010). Examination of the amino acid sequence of mouse and rat revealed differences in the amino acids at positions 353 and 82. Mice have histidine and humans have lysine at position 353 (F. Li, Li, Farzan, \& Harrison, 2005) which may explain the reason why SARS-CoV replicated less efficiently in murine cells (W. Li et al., 2004). At position 82, mice ACE2 has serine whereas human ACE2 has methionine, but this difference did not prevent the S-protein of SARS-CoV to bind mice cells and internalize but reduced permissiveness of these cells to infection, thus, making it semi-permissive to the SARS-CoV. Therefore, there is a need to generate "transgenic" mice or mouse should be adapted to become permissive to SARS-CoV infection.

Various transgenic mouse models like mice expressing the human ACE2 (hACE2) receptor and transgenic hACE2 under the control of an epithelial cell-specific promoter K18, showed infectivity with disease pathogenesis similar to that in humans (Bao et al., 2020; McCray et al., 2007), making them suitable for pathogenesis studies and evaluation of vaccines and other therapeutics against SARS-CoVs. The genetically engineered mice expressing the human ACE-2 (hACE2) were suitable for SARS-CoV infection and produced mortality (Dediego et al., 2008). Different contract research companies have produced hACE-2 expressing mice models and are already supplying it for SARS-CoV-2 studies. Taconic Biosciences, Rensselaer, New York, is supporting $\mathrm{CoV}$ research by providing ACE2-expressing mice that have been transplanted with human leukocyte antigen (HLA). The Jackson Laboratory (JAX), Maine, Florida is working to provide transgenic mouse expressing hACE-2 that were originally developed by Dr. Stanley Perlman at the University of Iowa. A study by Bao et. al . have used the mice model for SARS-CoV-2 and reported that transgenic hACE2 mice, when inoculated with BetaCoV/Wuhan/IVDC-HB-01/2020|EPI_ISL_402119 strain, developed clinical signs of COVID-19, including weight loss and interstitial pneumonia with histopathological signs in lungs(Table 1) (Bao et al., 2020). Another study by Sheahan et. al. showed that an orally bioavailable broad-spectrum, ribonucleoside analog $\beta$-D-N4-hydroxycytidine (NHC, EIDD-1931), is able to inhibit SARS$\mathrm{CoV}-2$ replication. Following intranasal challenge with a mouse-adapted 2019-nCoV/USA-WA1/2020 strain of SARS-CoV-2 virus; resulted in such as nasal congestion \& difficulty in breathing that have been reported in COVID-19 patients (Sheahan et al., 2020).(Table 1) . Researchers at the University of Pittsburgh School of Medicine have developed a vaccine candidate "PittCoVacc" (Pittsburgh CoV Vaccine) using in vitro generated fragments of viral protein. Administration of the vaccine to transgenic BABL/c mice resulted in the successful production of neutralizing antibodies against SARS-CoV-2 (E. Kim et al., 2020). Researchers at the NIH tested a mRNA vaccine developed by Moderna in Phase I clinical trials and confirmed immune responses by natural infection, which is now in its Phase II trial ("Moderna Moderna announces funding award from CEPI to accelerate development of messenger RNA (mRNA) vaccine against novel coronavirus; 2020. [accessed 2020 February15]

,"). administration of an inactivated SARS-CoV-2 vaccine, PiCoVacc, to ten BALB/c mice at multiple doses on day-0 and day-7 produced a good amount of SARS-CoV-2 spike and Receptor Binding Domain -specific immunoglobulin G (Ig G) responses (Q. Gao et al., 2020). All these studies signify the importance of mouse models in the testing of vaccines against SARS-CoV-2.

The major limitation with mice is that they are partially permissive to SARS-CoV infection due to the differences in the residues in ACE2 that are required for the cellular attachment and entry of SARS-CoV (F. Li 
et al., 2005). Mice adapted SARS-CoV-2 strains are suitable for use in pathogenesis, vaccine and therapeutic studies (Table 2). Altogether certain genetically engineered mice models can be useful in pathogenesis studies and testing vaccines and antivirals because of their small size, body weight, easy availability, and cost effectiveness for initial studies including high throughput screening.

\subsection{Hamster Model:}

Golden Syrian hamsters are rodents that belong to the hamster subfamily and are widely used in research related to human diseases, accounting for $19 \%$ of research in the U.S ("The Laboratory Rabbit, Guinea Pig, Hamster, and Other Rodents," 2012). These hamsters showed productive viral replication as well as pathological signs in lungs and disease pathogenesis when challenged with SARS-CoV. However, despite the fact that lung pathology looked similar to that in humans, hamsters did not recapitulate clinical disease or mortality in SARS-CoV infection (Roberts et al., 2006). Many other studies used different strains Urbani, HKU-39849, Frankfurt 1, and a recombinant clone GD03T0013 but failed to recapitulate the SARS-CoV-2 mediated fatality in hamsters (Roberts et al., 2008). Collectively, these studies demonstrate that the hamster represents a suitable model for SARS-CoV infection but is not suitable to model severe disease that is at times fatal in the human.

Hamsters support SARS-CoV-2 infections (J. F. Chan et al., 2020) as shown recently. In a study from Hong Kong, 8 hamsters were infected with a viral isolate purified from the nasopharyngeal aspirate specimen of a laboratory-confirmed COVID-19 patient. Clinical signs included weight loss, ruffled furs, and stressed breathing with high viral loads in the hamster's lungs and intestines. Histopathology examination revealed patches of inflammation and inflammatory cells with pleural invaginations in lung tissues (J. F. Chan et al., 2020) (Table 1). Another study used hamsters as a model to understand the mechanism of intra-species transmission (Sia SF, 2020). In this study, nine hamsters were infected intranasally with BetaCoV/Hong Kong/VM20001061/2020 virus where peak viral load was attained at day 2 post-infection in nasal washes, lungs, and fecal samples. Histopathological changes like consolidation and infiltration in lungs, kidneys, and intestines were detectable 7 days post-infection. At 24 hours post-inoculation, 3 of the experimentally infected animals were group housed with 3 naïve hamsters and after remaining in full contact for one day; they successfully transmitted the infection to naïve hamsters with substantial viral loads in nasal swabs, and clinical signs including weight loss and breathing distress (Table 1). At Day-13 post-contact, both donors and contact hamsters had developed neutralizing antibodies against SARS-CoV-2 (Sia SF, 2020). These studies clearly suggest that hamsters can be used to better understand the transmissibility of the virus.

The sequence of hamster ACE2 revealed the presence of asparagine $(\mathrm{N})$ at position 82, which contrasts with human ACE2 that has lysine $(\mathrm{K})$ at this position. Although hamsters were permissible for SARS-CoV and SARS-CoV-2 infections, they did not show severe fatal disease as seen in the human, which may be due to the amino acid change at position 82. Also, there is a lack of sequence data and other tools needed to carry out experiments in hamsters. Despite these shortcomings, hamsters may be used as models for SARS-CoV-2 transmission and consequently immunoprophylaxis studies because of their permissiveness to infection.

\subsection{Ferret Model:}

Ferrets have been used mainly in respiratory disease related studies because their lungs share a lot of similarity to that of humans (Vinegar, Sinnett, Kosch, \& Miller, 1985). Ferrets are also a popular animal model because they can mimic clinical symptoms of the SARS-CoVs such as coughing and fever. They have been previously used in Influenza (Lee et al., 2020) and Swine Influenza virus studies (van den Brand et al., 2010). Ferrets are permissive to SARS-CoV infection (Martina et al., 2003; Weingartl et al., 2004) and may be a potential model for the study of the SARS-CoV-2. Like mice models, ferrets were shown to support SARS-CoV replication with varying degrees of clinical signs but without significant mortality. When ferrets were infected with SARS-CoV at a high dose, they showed productive infection in the lungs, trachea, and nasal turbinates (Martina et al., 2003). Viral replication peaked in the lungs on days 5 or 6 as seen in humans, but another study using the same conditions failed to produce infection and mortality (Weingartl et al., 2004). 
Ferrets may be a suitable model to study SARS-CoV-2 pathogenesis and human-human transmission (Y. I. Kim et al., 2020; J. Shi et al., 2020). Shi et.al tested the susceptibility of ferrets to SARS-CoV-2 by infecting pairs of ferrets by two viral strains; SARS-CoV-2/F13/environment/2020/Wuhan (F13-E) or SARS-CoV2/CTan/human/2020/Wuhan (CTan-H) intranasally with $10^{5}$ plaque-forming units. After four days of inoculation, the animals were euthanized and tissues from the nasal turbinate, soft palate, tonsils, trachea, lung, heart, liver, spleen, kidneys, pancreas, small intestine, and brain were collected. Viral RNA was detected in areas of the upper respiratory tract- nasal turbinate, soft palate and tonsils (J. Shi et al., 2020). Another study from Korea showed that when infected intranasally with NMC-nCoV02, a strain isolated from a COVID-19 patient in South Korea, showed clinical signs two days after infection (Y. I. Kim et al., 2020). Although they showed an increment in body temperature, lethargy and occasional coughs all animals recovered day 8 post-infection (Table 1) . In follow-up studies, naïve ferrets were exposed to the infected ones to study the transmission dynamics. Interestingly, nasal swabs and saliva samples of the exposed ferrets showed high viral loads. In support of this, another study from the Netherlands demonstrated aerosol mediated transmission of SARS-CoV-2 from infected to naive exposed ferrets (Mathilde Richard, 2020) (Table 1) . These studies also showed that the pathogenicity of the virus was the same in the inoculated and later exposed ferrets. These studies showed the rapidity of virus transmission and the requirement of the appropriate distancing to avoid getting infected.

Ferrets are permissive for SARS-CoV-2 infection, but they are unable to produce clinical signs and symptoms with the same degree of severity as seen in humans. Other difficulties in working with ferrets are their larger size compared to mice and hamsters, difficulty in handling, expensive and require reagents that are unique to them. Nonetheless, ferrets can reproduce the virus dynamics of infection and transmission pattern (Table 2). The respiratory illness seen in ferrets resemble humans because their lungs are proportionately larger compared to other organs in their body. Moreover, their lungs abundantly express ACE2 protein similar to human lungs, which make them excellent models to study the early events in SARS-CoV-2 attachment and entry into host cells (PETERS). Further, ferrets can cough and sneeze and in doing so transmit the disease to nearby ferrets via aerosol /droplets, which makes them useful in transmission studies. Furthermore, their immune systems share a lot of similarities with the human, thereby making them potential animal models for testing vaccines, therapeutics and antivirals against SARS-CoV-2. Finally, the fact that ferrets are long-lived animals as makes them well suited to study the impact of aging on COVID-19 pathogenesis.

\subsection{Non-Human Primate (NHP) Models}

Several species of NHP's have been used in SARS-CoV and MERS-CoV studies. This includes old world monkeys such as rhesus macaques, cynomolgus macaques, and African Green monkeys, as well as new world monkeys that include the common marmosets, squirrel monkeys, and mustached tamarins (Lawler et al., 2006; McAuliffe et al., 2004; Qin et al., 2005). Squirrel monkeys and mustached tamarins are not permissive to SARS-CoV (Roberts \& Subbarao, 2006). MERS-CoV can replicate in only rhesus macaques and the common marmosets (de Wit et al., 2013; Falzarano et al., 2014; Yao et al., 2014). In a study that utilized cynomolgus macaques for SARS-CoV studies, virus was retrieved from nasal secretions and lungs samples via RT-PCR including the detection of pulmonary pneumonia, which which resembled the human disease (Lawler et al., 2006). African Green monkeys, cynomolgus macaques, and rhesus macaques infected with SARS-CoV Urbani strain did not develop clinical signs but viral replication was detected in nasal swabs and tracheal lavage samples (McAuliffe et al., 2004). The virus replicated to the highest titer in African Green macaques followed by cynomolgus macaques and then rhesus macaques. Infection of the common marmoset with SARS$\mathrm{CoV}$ Urbani resulted in mild clinical disease with the development of fever and diarrhea (Greenough et al., 2005). High levels of viral RNA were detected in lung samples on Days 4 and 7 after infection together with the presence of both pulmonary (interstitial pneumonia) and hepatic pathology. These macaques developed significant hepatic lesions on Days 4 and 7-post infection. The marmoset was the only NHP that showed liver pathology resembling that described in humans (Greenough et al., 2005).

The rhesus macaque and common marmoset are susceptible to MERS-CoV infection and show a wide spectrum of disease manifestations (de Wit et al., 2013; Falzarano et al., 2014). When infected intratracheally 
with a high dose of the EMC-2012 virus strain, rhesus macaques developed mild clinical signs such as anorexia, respiratory distress, and elevated WBCs on day 1-2 post-infection. Viral RNA could not be detected in the kidney or bladder (Yao et al., 2014). Another study by Falzarano et.al. used marmosets where the infection was done via intranasal, oral and ocular routes resulting in high virus titers (Falzarano et al., 2014). The animals showed respiratory distress, fever, nausea and lethargy at 4-6 days of infection. Viral RNA was detected from the throat and nasal swabs. Out of 9 marmosets used in the study, two of them developed multiple organ failure (kidney, liver and heart). Thus, from these studies, it was suggested that NHP models could provide deeper insights into the virus-induced pathology associated with severe Human Coronavirus infections. In summary, African Green Monkeys and Rhesus macaques were identified as good models for SARS-CoV replication studies, Among the two, Rhesus macaques showed similar viral replication kinetics that were consistent with the MERS-CoV replication in humans. However, the common marmoset remains the best model to study disease severity and multiple organ failure in both SARS-CoV and MERS-CoVs.

A recent study by Bao et. al., used the nonhuman primate models with SARS-CoV-2 infection followed by a repeat challenge with the same virus to ascertain the possibility of reinfection (Linlin Bao, 2020). In this study four adult Chinese rhesus macaques were intratracheally challenged with SARS-CoV-2/WH$09 /$ human/2020/CHN at $1 \times 10^{6}$ TCID50 via intratracheal route. Weight loss, reduced appetite, increased respiration rate, and hunched posture was observed and the viral loads from nasal and anal swabs revealed peak viremia (RNA) at 3 days post-infection (Table 1). After 28 days, two infected monkeys were intratracheally challenged with the same dose $\left(1 \times 10^{6}\right.$ TCID50) of SARS-CoV-2 to verify the possibility of reinfection. Viral loads in nasopharyngeal and anal swabs tested negative after re-exposure a SARS-CoV-2. The presence of the high levels of neutralizing antibodies in infected animals revealed that they had protective antibodies. PiCoVacc, a purified inactivated SARS-CoV-2 vaccine candidate, was tested in Rhesus macaques and showed good immunogenic response (Q. Gao et al., 2020) (Table 1). The vaccine candidate neutralized ten representative SARS-CoV-2 strains and offered complete protection in rhesus macaques. A second set of studies was performed in the rhesus macaque model to test the efficacy of a DNA vaccine candidate against SARS-CoV-2 (J. Yu et al., 2020). A total of 35 adult rhesus macaques were injected with the DNA vaccine candidates, with various constructs of SARS-CoV-2 proteins such as $\mathrm{S}(\mathrm{n}=4)$, S.dCT $(\mathrm{n}=4)$, S.dTM $(\mathrm{n}=4), \mathrm{S} 1(\mathrm{n}=4), \operatorname{RBD}(\mathrm{n}=4)$, S.dTM.PP $(\mathrm{n}=5)$ and Control $(\mathrm{n}=10)$, intramuscularly, and after 6 weeks they were challenged with $1.1 \times 10^{4}$ PFU SARS-CoV-2 intratracheally and intranasally. Nasal swabs and bronchoalveolar lavage (BAL) taken from both control and vaccinated animals found lower viral RNA in the vaccinated groups compared to the control animals. Furthermore, using the same control animals Chandrashekar et.al, showed development of protective immunity in SARS-CoV-2 infected macaques when the same animals were challenged a second time with the same virus (Chandrashekar et al., 2020). In this study 9 adult rhesus macaques, divided into three groups, were inoculated with $1.1 \times 10^{6} \mathrm{PFU}(\mathrm{n}=3)$, $1.1 \times 105 \mathrm{PFU}(\mathrm{n}=3) \mathrm{PFU}$ or $1.1 \times 10^{4} \mathrm{PFU}(\mathrm{n}=3)$ SARS-CoV-2 USA-WA1/2020 intranasally and intratracheally. Two days post infection; viral RNA was detected in bronchoalveolar lavage (BAL) and nasal swabs with animals experiencing loss of appetite and transient lymphopenia and neutropenia. Around day 35-post infection, these animals were re-inoculated with the same dose of SARS-CoV-2 as initial challenge. Interestingly, 2 days after the second challenge, the viral RNA in BAL was more than five logs lower than that detected after the primary challenge suggesting that recovery from the primary exposure helps the development of protective immunity against secondary exposure(Table 1). Another, research group from Montana, USA had shown infection in Rhesus Macaque in the upper and lower respiratory tract (Vincent J. Munster, 2020). In their study, Rhesus macaques were infected with SARS-CoV-2 isolate nCoV-WA1-2020 through various routes (intranasal, oral, ocular, and intratracheal routes), showed reduced appetite, hunched posture, pale appearance and dehydration(Table 1). The viral loads were highest in the nasal swabs followed by throat and rectal swabs. Histopathology revealed multifocal interstitial pneumonia, edematous alveoli and type II pneumocyte hyperplasia. Chest radiographs revealed the presence of pulmonary infiltrates and consolidation, which is the main clinical sign of COVID-19 in infected rhesus macaques. Near identical clinical signs and histopathology were observed when Rhesus macaques were challenged with a similar virus strain to show the therapeutic efficacy of Remdesivir (Brandi N. Williamson, 2020). The other two studies showed age-related correlations in Rhesus (P. Yu et al., 2020) and Cynomolgus macaques (Rockx et al., 
2020) and have demonstrated the impact of comorbidities on SARS-CoV-2 disease severity (Table 1) . More recently, African Green monkeys (AGMs)(Woolsey et al., 2020) and baboons (Dhiraj Kumar Singh, 2020) were demonstrated to show more pronounced respiratory disease than rhesus macaques suggesting that both AGMs and baboons may be the models of choice to test novel immunomodulatory therapies to reduce disease severity. Interestingly, African green monkeys were successfully infected with a lower SARSCoV-2 inoculum compared to rhesus macaques. Unlike rodents, macaques, baboons and AGMs are larger in size, require a larger experimental space, and costly as compared to the other animal models. However, macaques develop respiratory disease that is comparable to the human disease and therefore represent better translational animal models to study pathogenesis, vaccine efficacy, therapeutics, co-infections, including the impact of age and other preexisting co-morbidities on SARS-CoV-2 disease course.

\section{Conclusions and future perspectives}

Intensive efforts have been invested in the short timespan after the outbreak of COVID-19 to characterize and develop anti-SARS-CoV-2 therapeutics. Many drugs are being developed or being repurposed with varying degrees of success in in-vitro and clinical trials. As the speed of discovering the drugs and vaccines is increasing, understanding their safety and effectiveness is urgently needed to control the spread of the SARSCoV-2 infection. However, many questions still need to be answered regarding the route of transmission of SARS-CoV-2. Are other routes like fecal, sexual or mother-to-child transmission involved? The disease has dynamic outcomes, which has made it challenging to understand the pathogenesis. Why does the disease have higher infectivity than MERS and SARS? Why are elderly people and people with underlying conditions more susceptible? There are many unknowns regarding the comorbidities and coinfections of SARS-CoV-2. Finally, there are questions as to why some repurposed antivirals or drugs are effective in some individuals in the treatment of COVID-19. In order to answer these questions, in vivo studies using the best animal models are needed because it is impossible to ask all these questions in human clinical studies. Because of the large variability in the genetic makeup of humans' it is impossible to understand mechanisms. Animal models like ferrets, mice, and hamsters can aid in answering many questions pertaining to the mechanism of action of antivirals, efficacy and safety of vaccines and the impact of comorbidities on COVID-19 pathogenesis. Several animal models can be used to answer these questions; however, it is possible that no single animal will be able to answer all the human translational questions due to inherent differences in the development and physiology of the organism. Furthermore, there is a considerable amount of variability among the animals such as differences in their biology, genetics, level of ACE2 receptor expression, all of which can influence the rate of infection.

\section{Conflicts of Interests}

Authors declared no conflict of interest exists.

\section{ETHICAL APPROVAL}

We declare ethical statement is not applicable

\section{DATA AVALIABILITY STATEMENT}

All the data to support the findings are within the manuscript.

ACKNOWLEDGEMENTS: This work is partially supported by National Institute of Allergy and Infectious Diseases Grant R01 AI129745, and Frances E. Lageschulte and Evelyn B. Weese New Frontiers in Medical Research Fund to SNB.

\section{References}

Acharya, A., Kevadiya, B. D., Gendelman, H. E., \& Byrareddy, S. N. (2020). SARS-CoV-2 Infection Leads to Neurological Dysfunction. J Neuroimmune Pharmacol, 15 (2), 167-173. doi:10.1007/s11481-020-09924-9

Agostini, M. L., Andres, E. L., Sims, A. C., Graham, R. L., Sheahan, T. P., Lu, X., . . Denison, M. R. (2018). 
Coronavirus Susceptibility to the Antiviral Remdesivir (GS-5734) Is Mediated by the Viral Polymerase and the Proofreading Exoribonuclease. mBio, 9 (2). doi:10.1128/mBio.00221-18

Arashiro, T., Nakamura, S., Asami, T., Mikuni, H., Fujiwara, E., Sakamoto, S., . . Saito, H. (2020). SARS-CoV-2 and Legionella Co-infection in a Person Returning from a Nile Cruise. $J$ Travel Med. doi:10.1093/jtm/taaa053

Azekawa, S., Namkoong, H., Mitamura, K., Kawaoka, Y., \& Saito, F. (2020). Co-infection with SARS-CoV-2 and influenza A virus.IDCases, 20 , e00775. doi:10.1016/j.idcr.2020.e00775

Bao, L., Deng, W., Huang, B., Gao, H., Liu, J., Ren, L., . . Qin, C. (2020). The pathogenicity of SARS-CoV-2 in hACE2 transgenic mice.Nature . doi:10.1038/s41586-020-2312-y

Bassetti, M., Vena, A., \& Giacobbe, D. R. (2020). The novel Chinese coronavirus (2019-nCoV) infections: Challenges for fighting the storm.Eur J Clin Invest, 50 (3), e13209. doi:10.1111/eci.13209

Beigel, J. H., Tomashek, K. M., Dodd, L. E., Mehta, A. K., Zingman, B. S., Kalil, A. C., . . . Members, A.-S. G. (2020). Remdesivir for the Treatment of Covid-19 - Preliminary Report. $N$ Engl J Med . doi:10.1056/NEJMoa2007764

Bhatnagar, T., Murhekar, M. V., Soneja, M., Gupta, N., Giri, S., Wig, N., \& Gangakhedkar, R. (2020). Lopinavir/ritonavir combination therapy amongst symptomatic coronavirus disease 2019 patients in India: Protocol for restricted public health emergency use. Indian J Med Res, 151 (2 \& 3), 184-189. doi:10.4103/ijmr.IJMR_502_20

Bhatraju, P. K., Ghassemieh, B. J., Nichols, M., Kim, R., Jerome, K. R., Nalla, A. K., . . . Mikacenic, C. (2020). Covid-19 in Critically Ill Patients in the Seattle Region - Case Series. $N$ Engl J Med . doi:10.1056/NEJMoa2004500

Bogoch, II, Watts, A., Thomas-Bachli, A., Huber, C., Kraemer, M. U. G., \& Khan, K. (2020). Pneumonia of unknown aetiology in Wuhan, China: potential for international spread via commercial air travel. $J$ Travel Med, 27 (2). doi:10.1093/jtm/taaa008

Brandi N. Williamson, F. F., Benjamin Schwarz, Kimberly Meade-White, Danielle P. Porter, Jonathan Schulz, Neeltje van Doremalen, Ian Leighton, Claude Kwe Yinda, Lizzette Pérez-Pérez, Atsushi Okumura, Jamie Lovaglio, Patrick W. Hanley, Greg Saturday, Catharine M. Bosio, Sarah Anzick, Kent Barbian, Tomas Cihlar, Craig Martens, Dana P. Scott, View ORCID ProfileVincent J. Munster, Emmie de Wit. (2020). Clinical benefit of remdesivir in rhesus macaques infected with SARS-CoV-2. doi:doi.org/10.1101/2020.04.15.043166

Chan, J. F., Yao, Y., Yeung, M. L., Deng, W., Bao, L., Jia, L., . . Yuen, K. Y. (2015). Treatment With Lopinavir/Ritonavir or Interferon-beta1b Improves Outcome of MERS-CoV Infection in a Nonhuman Primate Model of Common Marmoset. J Infect Dis, 212 (12), 1904-1913. doi:10.1093/infdis/jiv392

Chan, J. F., Zhang, A. J., Yuan, S., Poon, V. K., Chan, C. C., Lee, A. C., . . Yuen, K. Y. (2020). Simulation of the clinical and pathological manifestations of Coronavirus Disease 2019 (COVID-19) in golden Syrian hamster model: implications for disease pathogenesis and transmissibility. Clin Infect Dis . doi:10.1093/cid/ciaa325

Chan, J. F.-W., Kok, K.-H., Zhu, Z., Chu, H., To, K. K.-W., Yuan, S., \& Yuen, K.-Y. (2020). Genomic characterization of the 2019 novel human-pathogenic coronavirus isolated from a patient with atypical pneumonia after visiting Wuhan. Emerging microbes 83 infections, 9 (1), 221-236. doi:10.1080/22221751.2020.1719902

Chan, P. K., \& Chan, M. C. (2013). Tracing the SARS-coronavirus.J Thorac Dis, 5 Suppl 2 , S118-121. doi:10.3978/j.issn.2072-1439.2013.06.19

Chandrashekar, A., Liu, J., Martinot, A. J., McMahan, K., Mercado, N. B., Peter, L., . . . Barouch, D. H. (2020). SARS-CoV-2 infection protects against rechallenge in rhesus macaques. Science . doi:10.1126/science.abc4776 
Chu, C. M., Cheng, V. C., Hung, I. F., Wong, M. M., Chan, K. H., Chan, K. S., . . Group, H. U. S. S. (2004). Role of lopinavir/ritonavir in the treatment of SARS: initial virological and clinical findings. Thorax, 59 (3), 252-256. doi:10.1136/thorax.2003.012658

Corman, V. M., Muth, D., Niemeyer, D., \& Drosten, C. (2018). Hosts and Sources of Endemic Human Coronaviruses. Adv Virus Res, 100 , 163-188. doi:10.1016/bs.aivir.2018.01.001

Cucinotta, D., \& Vanelli, M. (2020). WHO Declares COVID-19 a Pandemic.Acta Biomed, 91 (1), 157-160. doi:10.23750/abm.v91i1.9397

Cui, J., Li, F., \& Shi, Z. L. (2019). Origin and evolution of pathogenic coronaviruses. Nat Rev Microbiol, 17 (3), 181-192. doi:10.1038/s41579-018-0118-9

de Wit, E., Rasmussen, A. L., Falzarano, D., Bushmaker, T., Feldmann, F., Brining, D. L., . . Munster, V. J. (2013). Middle East respiratory syndrome coronavirus (MERS-CoV) causes transient lower respiratory tract infection in rhesus macaques. Proc Natl Acad Sci U S A, 110 (41), 16598-16603. doi:10.1073/pnas.1310744110

Dediego, M. L., Pewe, L., Alvarez, E., Rejas, M. T., Perlman, S., \& Enjuanes, L. (2008). Pathogenicity of severe acute respiratory coronavirus deletion mutants in hACE-2 transgenic mice. Virology, 376 (2), 379-389. doi:10.1016/j.virol.2008.03.005

Denison, M. R., Graham, R. L., Donaldson, E. F., Eckerle, L. D., \& Baric, R. S. (2011). Coronaviruses: an RNA proofreading machine regulates replication fidelity and diversity. $R N A$ Biol, 8 (2), 270-279. doi:10.4161/rna.8.2.15013

Developing Therapeutics and Vaccines for Coronaviruses. [Press release]. Retrieved from https://www.niaid.nih.gov/diseases-conditions/coronaviruses-therapeutics-vaccines

Dhiraj Kumar Singh, S. R. G., Bindu Singh, Journey Cole, Kendra J. Alfson, Elizabeth Clemmons, Michal Gazi, Olga Gonzalez, Ruby Escobedo, Tae-Hyung Lee, Ayan Chatterjee, Yenny Goez-Gazi, Riti Sharan, Rajesh Thippeshappa, Maya Gough, Cynthia Alvarez, Alyssa Blakley, Justin Ferdin, Carmen Bartley, Hilary Staples, Laura Parodi, Jessica Callery, Amanda Mannino, Benjamin Klaffke, Priscilla Escareno, Roy N. Platt II, Vida Hodara, Julia Scordo, Adelekan Oyejide, Dharani K. Ajithdoss, Richard Copin, Alina Baum, Christos Kyratsous, Xavier Alvarez, Bruce Rosas, Mushtaq Ahmed, Anna Goodroe, John Dutton, Shannan HallUrsone, Patrice A. Frost, Andra K. Voges, Corinna N. Ross, Ken Sayers, Christopher Chen, Cory Hallam, Shabaana A. Khader, Makedonka Mitreva, View ORCID ProfileTimothy J. C. Anderson, Luis MartinezSobrido, Jean L. Patterson, Joanne Turner, Jordi B. Torrelles, Edward J. Dick Jr., Kathleen Brasky, Larry S. Schlesinger, Luis D. Giavedoni, Ricardo Carrion Jr., View ORCID ProfileDeepak Kaushal. (2020). SARS$\mathrm{CoV}-2$ infection leads to acute infection with dynamic cellular and inflammatory flux in the lung that varies across nonhuman primate species. doi:https://doi.org/10.1101/2020.06.05.13648

Falzarano, D., de Wit, E., Feldmann, F., Rasmussen, A. L., Okumura, A., Peng, X., . . Munster, V. J. (2014). Infection with MERS-CoV causes lethal pneumonia in the common marmoset. PLoS Pathog, 10 (8), e1004250. doi:10.1371/journal.ppat.1004250

Frieman, M. B., Chen, J., Morrison, T. E., Whitmore, A., Funkhouser, W., Ward, J. M., . . . Baric, R. S. (2010). SARS-CoV pathogenesis is regulated by a STAT1 dependent but a type I, II and III interferon receptor independent mechanism. PLoS Pathog, 6 (4), e1000849. doi:10.1371/journal.ppat.1000849

Fujiyama, A., Watanabe, H., Toyoda, A., Taylor, T. D., Itoh, T., Tsai, S. F., . . . Sakaki, Y. (2002). Construction and analysis of a human-chimpanzee comparative clone map. Science, 295 (5552), 131-134. doi:10.1126/science.1065199

Gao, H. N., Lu, H. Z., Cao, B., Du, B., Shang, H., Gan, J. H., . . Li, L. J. (2013). Clinical findings in 111 cases of influenza A (H7N9) virus infection. N Engl J Med, 368 (24), 2277-2285. doi:10.1056/NEJMoa1305584

Gao, Q., Bao, L., Mao, H., Wang, L., Xu, K., Yang, M., . . . Qin, C. (2020). Rapid development of an inactivated vaccine candidate for SARS-CoV-2. Science . doi:10.1126/science.abc1932 
Glass, W. G., Subbarao, K., Murphy, B., \& Murphy, P. M. (2004). Mechanisms of host defense following severe acute respiratory syndrome-coronavirus (SARS-CoV) pulmonary infection of mice. J Immunol, 173 (6), 4030-4039. doi:10.4049/jimmunol.173.6.4030

Gold, J. A. W., Wong, K. K., Szablewski, C. M., Patel, P. R., Rossow, J., da Silva, J., . . Jackson, B. R. (2020). Characteristics and Clinical Outcomes of Adult Patients Hospitalized with COVID-19 - Georgia, March 2020. MMWR Morb Mortal Wkly Rep, 69 (18), 545-550. doi:10.15585/mmwr.mm6918e1

Greenough, T. C., Carville, A., Coderre, J., Somasundaran, M., Sullivan, J. L., Luzuriaga, K., \& Mansfield, K. (2005). Pneumonitis and multi-organ system disease in common marmosets (Callithrix jacchus) infected with the severe acute respiratory syndrome-associated coronavirus. Am J Pathol, 167 (2), 455-463. doi:10.1016/S0002-9440(10)62989-6

Gretebeck, L. M., \& Subbarao, K. (2015). Animal models for SARS and MERS coronaviruses. Curr Opin Virol, 13 , 123-129. doi:10.1016/j.coviro.2015.06.009

Hamid, S., Mir, M. Y., \& Rohela, G. K. (2020). Novel coronavirus disease (COVID-19): a pandemic (epidemiology, pathogenesis and potential therapeutics). New Microbes New Infect, 35 , 100679. doi:10.1016/j.nmni.2020.100679

Hamming, I., Timens, W., Bulthuis, M. L., Lely, A. T., Navis, G., \& van Goor, H. (2004). Tissue distribution of ACE2 protein, the functional receptor for SARS coronavirus. A first step in understanding SARS pathogenesis. J Pathol, 203 (2), 631-637. doi:10.1002/path.1570

Hoffmann, M., Kleine-Weber, H., Schroeder, S., Kruger, N., Herrler, T., Erichsen, S., . . Pohlmann, S. (2020). SARS-CoV-2 Cell Entry Depends on ACE2 and TMPRSS2 and Is Blocked by a Clinically Proven Protease Inhibitor. Cell, 181 (2), 271-280 e278. doi:10.1016/j.cell.2020.02.052

Huang, C., Wang, Y., Li, X., Ren, L., Zhao, J., Hu, Y., . . . Cao, B. (2020). Clinical features of patients infected with 2019 novel coronavirus in Wuhan, China. Lancet, 395 (10223), 497-506. doi:10.1016/S01406736(20)30183-5

Ji, W., Wang, W., Zhao, X., Zai, J., \& Li, X. (2020). Cross-species transmission of the newly identified coronavirus 2019-nCoV. J Med Virol, 92 (4), 433-440. doi:10.1002/jmv.25682

Kim, E., Erdos, G., Huang, S., Kenniston, T. W., Balmert, S. C., Carey, C. D., . . Gambotto, A. (2020). Microneedle array delivered recombinant coronavirus vaccines: Immunogenicity and rapid translational development. EBioMedicine , 102743. doi:10.1016/j.ebiom.2020.102743

Kim, Y. I., Kim, S. G., Kim, S. M., Kim, E. H., Park, S. J., Yu, K. M., . . Choi, Y. K. (2020). Infection and Rapid Transmission of SARS-CoV-2 in Ferrets. Cell Host Microbe . doi:10.1016/j.chom.2020.03.023

The Laboratory Rabbit, Guinea Pig, Hamster, and Other Rodents. (2012).

Lawler, J. V., Endy, T. P., Hensley, L. E., Garrison, A., Fritz, E. A., Lesar, M., . . Paragas, J. (2006). Cynomolgus macaque as an animal model for severe acute respiratory syndrome. PLoS Med, 3 (5), e149. doi:10.1371/journal.pmed.0030149

Lee, L. Y. Y., Zhou, J., Frise, R., Goldhill, D. H., Koszalka, P., Mifsud, E. J., . . B Barclay, W. S. (2020). Baloxavir treatment of ferrets infected with influenza A(H1N1)pdm09 virus reduces onward transmission. PLoS Pathog, 16 (4), e1008395. doi:10.1371/journal.ppat.1008395

Lewis, D. (2020). Is the coronavirus airborne? Experts can't agree.Nature, 580 (7802), 175. doi:10.1038/d41586-020-00974-w

Li, F., Li, W., Farzan, M., \& Harrison, S. C. (2005). Structure of SARS coronavirus spike receptor-binding domain complexed with receptor.Science, 309 (5742), 1864-1868. doi:10.1126/science.1116480 
Li, Q., Guan, X., Wu, P., Wang, X., Zhou, L., Tong, Y., . . . Feng, Z. (2020). Early Transmission Dynamics in Wuhan, China, of Novel Coronavirus-Infected Pneumonia. N Engl J Med, 382 (13), 1199-1207. doi:10.1056/NEJMoa2001316

Li, W., Greenough, T. C., Moore, M. J., Vasilieva, N., Somasundaran, M., Sullivan, J. L., . . Choe, H. (2004). Efficient replication of severe acute respiratory syndrome coronavirus in mouse cells is limited by murine angiotensin-converting enzyme 2. J Virol, 78 (20), 11429-11433. doi:10.1128/JVI.78.20.11429-11433.2004

Li, W., Moore, M. J., Vasilieva, N., Sui, J., Wong, S. K., Berne, M. A., . . Farzan, M. (2003). Angiotensinconverting enzyme 2 is a functional receptor for the SARS coronavirus. Nature, 426 (6965), 450-454. doi:10.1038/nature02145

Linlin Bao, W. D., Hong Gao, Chong Xiao, Jiayi Liu, Jing Xue, Qi Lv, Jiangning Liu, Pin Yu, Yanfeng Xu, Feifei Qi, Yajin Qu, Fengdi Li, Zhiguang Xiang, Haisheng Yu, Shuran Gong, Mingya Liu, Guanpeng Wang, Shunyi Wang, Zhiqi Song, Wenjie Zhao, Yunlin Han, Linna Zhao, Xing Liu, Qiang Wei, Chuan Qin. (2020). Reinfection could not occur in SARS-CoV-2 infected rhesus macaques. doi:https://doi.org/10.1101/2020.03.13.990226

Lu, Y. R., Wang, L. N., Jin, X., Chen, Y. N., Cong, C., Yuan, Y., . . Cheng, J. Q. (2008). A preliminary study on the feasibility of gene expression profile of rhesus monkey detected with human microarray. Transplant Proc, 40 (2), 598-602. doi:10.1016/j.transproceed.2008.01.029

Luke, T., Wu, H., Zhao, J., Channappanavar, R., Coleman, C. M., Jiao, J. A., . . Frieman, M. B. (2016). Human polyclonal immunoglobulin G from transchromosomic bovines inhibits MERS-CoV in vivo. Sci Transl Med, 8 (326), 326ra321. doi:10.1126/scitranslmed.aaf1061

Mao, L., Jin, H., Wang, M., Hu, Y., Chen, S., He, Q., . . . Hu, B. (2020). Neurologic Manifestations of Hospitalized Patients With Coronavirus Disease 2019 in Wuhan, China. JAMA Neurol . doi:10.1001/jamaneurol.2020.1127

Martina, B. E., Haagmans, B. L., Kuiken, T., Fouchier, R. A., Rimmelzwaan, G. F., Van Amerongen, G., . . Osterhaus, A. D. (2003). Virology: SARS virus infection of cats and ferrets. Nature, 425 (6961), 915. doi:10.1038/425915a

Mathilde Richard, A. K., Dennis de Meulder, Theo M. Bestebroer, Mart M. Lamers, Nisreen M.A. Okba, Martje Fentener van Vlissingen, Barry Rockx, Bart L. Haagmans, Marion P.G. Koopmans, Ron A.M. Fouchier, View ORCID ProfileSander Herfst. (2020). SARS-CoV-2 is transmitted via contact and via the air between ferrets. doi:doi.org/10.1101/2020.04.16.044503

McAuliffe, J., Vogel, L., Roberts, A., Fahle, G., Fischer, S., Shieh, W. J., . . Subbarao, K. (2004). Replication of SARS coronavirus administered into the respiratory tract of African Green, rhesus and cynomolgus monkeys. Virology, 330 (1), 8-15. doi:10.1016/j.virol.2004.09.030

McCray, P. B., Jr., Pewe, L., Wohlford-Lenane, C., Hickey, M., Manzel, L., Shi, L., . . Perlman, S. (2007). Lethal infection of K18-hACE2 mice infected with severe acute respiratory syndrome coronavirus. $J$ Virol, 81 (2), 813-821. doi:10.1128/JVI.02012-06

Meselson, M. (2020). Droplets and Aerosols in the Transmission of SARS-CoV-2. N Engl J Med, 382 (21), 2063. doi:10.1056/NEJMc2009324

Moderna Moderna announces funding award from CEPI to accelerate development of messenger RNA (mRNA) vaccine against novel coronavirus; 2020. [accessed 2020 February15]

. [Press release]. Retrieved from https://investors.modernatx.com/news-releases/news-releasedetails/moderna-announces-funding-award-cepi-accelerate-development

Mukherjee, R. (2020). Global efforts on vaccines for COVID-19: Since, sooner or later, we all will catch the coronavirus. J Biosci, 45 . 
Mulangu, S., Dodd, L. E., Davey, R. T., Jr., Tshiani Mbaya, O., Proschan, M., Mukadi, D., . . Team, P. C. S. (2019). A Randomized, Controlled Trial of Ebola Virus Disease Therapeutics. N Engl J Med, 381 (24), 2293-2303. doi:10.1056/NEJMoa1910993

Nanshan, Z. (2020) The new coronavirus is likely to come from game products such as bamboo rats and tadpoles. . Netease News. Jan 20, 2020.

Nicholls, J. M., Poon, L. L., Lee, K. C., Ng, W. F., Lai, S. T., Leung, C. Y., . . Peiris, J. S. (2003). Lung pathology of fatal severe acute respiratory syndrome. Lancet, 361 (9371), 1773-1778. doi:10.1016/s01406736(03)13413-7

Peiris, J. S., Lai, S. T., Poon, L. L., Guan, Y., Yam, L. Y., Lim, W., . . group, S. s. (2003). Coronavirus as a possible cause of severe acute respiratory syndrome. Lancet, 361 (9366), 1319-1325. doi:10.1016/s01406736(03)13077-2

PETERS, D. How Ferrets Are Helping Researchers Battle Covid-19. Retrieved from https://undark.org/2020/04/25/ferrets-covid-19/

Product Development Under the Animal Rule . (2015). Food and Drug Administration

Retrieved from https://www.fda.gov/regulatory-information/search-fda-guidance-documents/productdevelopment-under-animal-rule.

Qin, C., Wang, J., Wei, Q., She, M., Marasco, W. A., Jiang, H., . . . He, W. (2005). An animal model of SARS produced by infection of Macaca mulatta with SARS coronavirus. J Pathol, 206 (3), 251-259. doi:10.1002/path.1769

Raj, V. S., Mou, H., Smits, S. L., Dekkers, D. H., Muller, M. A., Dijkman, R., . . Haagmans, B. L. (2013). Dipeptidyl peptidase 4 is a functional receptor for the emerging human coronavirus-EMC.Nature, 495 (7440), 251-254. doi:10.1038/nature12005

Raj, V. S., Osterhaus, A. D., Fouchier, R. A., \& Haagmans, B. L. (2014). MERS: emergence of a novel human coronavirus. Curr Opin Virol, 5 , 58-62. doi:10.1016/j.coviro.2014.01.010

Roberts, A., Lamirande, E. W., Vogel, L., Jackson, J. P., Paddock, C. D., Guarner, J., . . . Subbarao, K. (2008). Animal models and vaccines for SARS-CoV infection. Virus Res, 133 (1), 20-32. doi:10.1016/j.virusres.2007.03.025

Roberts, A., Paddock, C., Vogel, L., Butler, E., Zaki, S., \& Subbarao, K. (2005). Aged BALB/c mice as a model for increased severity of severe acute respiratory syndrome in elderly humans. J Virol, 79 (9), 5833-5838. doi:10.1128/JVI.79.9.5833-5838.2005

Roberts, A., \& Subbarao, K. (2006). Animal models for SARS. Adv Exp Med Biol, 581 , 463-471. doi:10.1007/978-0-387-33012-9_83

Roberts, A., Thomas, W. D., Guarner, J., Lamirande, E. W., Babcock, G. J., Greenough, T. C., . . Ambrosino, D. M. (2006). Therapy with a severe acute respiratory syndrome-associated coronavirus-neutralizing human monoclonal antibody reduces disease severity and viral burden in golden Syrian hamsters. $J$ Infect Dis, 193 (5), 685-692. doi:10.1086/500143

Rockx, B., Kuiken, T., Herfst, S., Bestebroer, T., Lamers, M. M., Oude Munnink, B. B., . . Haagmans, B. L. (2020). Comparative pathogenesis of COVID-19, MERS, and SARS in a nonhuman primate model. Science . doi:10.1126/science.abb7314

Rothan, H. A., \& Byrareddy, S. N. (2020). The epidemiology and pathogenesis of coronavirus disease (COVID-19) outbreak. J Autoimmun, 109 , 102433. doi:10.1016/j.jaut.2020.102433

Scavone, C., Brusco, S., Bertini, M., Sportiello, L., Rafaniello, C., Zoccoli, A., . . . Capuano, A. (2020). Current pharmacological treatments for COVID-19: what's next? Br J Pharmacol . doi:10.1111/bph.15072 
Sean T. H. Liu, H.-M. L., Ian Baine, Ania Wajnberg, Jeffrey P. Gumprecht, Farah Rahman, Denise Rodriguez, Pranai Tandon, Adel Bassily-Marcus, Jeffrey Bander, Charles Sanky, Amy Dupper, Allen Zheng, Deena R. Altman, Benjamin K. Chen, Florian Krammer, Damodara Rao Mendu, Adolfo Firpo-Betancourt, Matthew A. Levin, Emilia Bagiella, Arturo Casadevall, Carlos Cordon-Cardo, Jeffrey S. Jhang, Suzanne A. Arinsburg, David L. Reich, Judith A. Aberg, View ORCID ProfileNicole M. Bouvier. (2020). Convalescent plasma treatment of severe COVID-19: A matched control study. [

]. doi:https://doi.org/10.1101/2020.05.20.20102236

Sheahan, T. P., Sims, A. C., Zhou, S., Graham, R. L., Pruijssers, A. J., Agostini, M. L., . . Baric, R. S. (2020). An orally bioavailable broad-spectrum antiviral inhibits SARS-CoV-2 in human airway epithelial cell cultures and multiple coronaviruses in mice. Sci Transl Med, 12 (541). doi:10.1126/scitranslmed.abb5883

Shi, H., Han, X., Jiang, N., Cao, Y., Alwalid, O., Gu, J., . . Zheng, C. (2020). Radiological findings from 81 patients with COVID-19 pneumonia in Wuhan, China: a descriptive study. Lancet Infect Dis, 20 (4), 425-434. doi:10.1016/S1473-3099(20)30086-4

Shi, J., Wen, Z., Zhong, G., Yang, H., Wang, C., Huang, B., . . . Bu, Z. (2020). Susceptibility of ferrets, cats, dogs, and other domesticated animals to SARS-coronavirus 2. Science, 368 (6494), 1016-1020. doi:10.1126/science.abb7015

Sia SF, Y. L., Chin AW, Fung K, Poon LL, Nicholls JM, Peiris M, Yen H. (2020). Pathogenesis and transmission of SARS-CoV-2 virus in golden Syrian hamsters. doi:10.21203/rs.3.rs-20774/v1

Subbarao, K., McAuliffe, J., Vogel, L., Fahle, G., Fischer, S., Tatti, K., . . Murphy, B. (2004). Prior infection and passive transfer of neutralizing antibody prevent replication of severe acute respiratory syndrome coronavirus in the respiratory tract of mice. $J$ Virol, 78 (7), 3572-3577. doi:10.1128/jvi.78.7.3572-3577.2004

Sui, J., Li, W., Murakami, A., Tamin, A., Matthews, L. J., Wong, S. K., . . Marasco, W. A. (2004). Potent neutralization of severe acute respiratory syndrome (SARS) coronavirus by a human mAb to S1 protein that blocks receptor association. Proc Natl Acad Sci U S A, 101 (8), 2536-2541. doi:10.1073/pnas.0307140101

Sun, H., Ning, R., Tao, Y., Yu, C., Deng, X., Zhao, C., . . Xu, D. (2020). Risk factors for mortality in 244 older adults with COVID-19 in Wuhan, China: a retrospective study. J Am Geriatr Soc . doi:10.1111/jgs.16533

Sutton, T. C., \& Subbarao, K. (2015). Development of animal models against emerging coronaviruses: From SARS to MERS coronavirus. Virology, 479-480 , 247-258. doi:10.1016/j.virol.2015.02.030

Takayama, K. (2020). In vitro and Animal Models for SARS-CoV-2 research. doi:https://doi.org/10.1016/j.tips.2020.05.005

Touzard-Romo, F., Tape, C., \& Lonks, J. R. (2020). Co-infection with SARS-CoV-2 and Human Metapneumovirus. R I Med J (2013), 103 (2), 75-76.

van den Brand, J. M., Stittelaar, K. J., van Amerongen, G., Rimmelzwaan, G. F., Simon, J., de Wit, E., . . . Osterhaus, A. D. (2010). Severity of pneumonia due to new H1N1 influenza virus in ferrets is intermediate between that due to seasonal H1N1 virus and highly pathogenic avian influenza H5N1 virus. J Infect Dis, 201 (7), 993-999. doi:10.1086/651132

Vincent J. Munster, F. F., Brandi N. Williamson, Neeltje van Doremalen, Lizzette Pérez-Pérez, Jonathan Schulz, Kimberly Meade-White, Atsushi Okumura, Julie Callison, Beniah Brumbaugh, Victoria A. Avanzato, Rebecca Rosenke, Patrick W. Hanley, Greg Saturday, Dana Scott, Elizabeth R. Fischer, Emmie de Wit. (2020). Respiratory disease and virus shedding in rhesus macaques inoculated with SARS-CoV-2. doi:doi.org/10.1101/2020.03.21.001628

Vinegar, A., Sinnett, E. E., Kosch, P. C., \& Miller, M. L. (1985). Pulmonary physiology of the ferret and its potential as a model for inhalation toxicology. Lab Anim Sci, 35 (3), 246-250. 
Wang, X., Cao, R., Zhang, H., Liu, J., Xu, M., Hu, H., . . Wang, M. (2020). The anti-influenza virus drug, arbidol is an efficient inhibitor of SARS-CoV-2 in vitro. Cell Discov, 6 , 28. doi:10.1038/s41421-020-0169-8

Weingartl, H., Czub, M., Czub, S., Neufeld, J., Marszal, P., Gren, J., . . . Cao, J. (2004). Immunization with modified vaccinia virus Ankara-based recombinant vaccine against severe acute respiratory syndrome is associated with enhanced hepatitis in ferrets. $J$ Virol, 78 (22), 12672-12676. doi:10.1128/JVI.78.22.1267212676.2004

What explains Covid-19's lethality for the elderly? Scientists look to 'twilight' of the immune system. (2020). [Press release]. Retrieved from https://www.statnews.com/2020/03/30/what-explains-coronavirus-lethalityfor-elderly/

Woo, P. C., Lau, S. K., Lam, C. S., Lau, C. C., Tsang, A. K., Lau, J. H., . . Yuen, K. Y. (2012). Discovery of seven novel Mammalian and avian coronaviruses in the genus deltacoronavirus supports bat coronaviruses as the gene source of alphacoronavirus and betacoronavirus and avian coronaviruses as the gene source of gammacoronavirus and deltacoronavirus. $J$ Virol, 86 (7), 3995-4008. doi:10.1128/JVI.06540-11

Woolsey, C., Borisevich, V., Prasad, A. N., Agans, K. N., Deer, D. J., Dobias, N. S., . . Cross, R. W. (2020). Establishment of an African green monkey model for COVID-19. bioRxiv . doi:10.1101/2020.05.17.100289

World Health Organization . Geneva (Switzerland): World Health Organization; 2003. Summary of probable SARS cases with onset of illness from 1 November 2002 to 31 July 2003

World Health Organization . Geneva (Switzerland): World Health Organization; 2019. MERS situation update, December 2019.

Xiao, K., Zhai, J., Feng, Y., Zhou, N., Zhang, X., Zou, J. J., . . Shen, Y. (2020). Isolation of SARS-CoV2-related coronavirus from Malayan pangolins. Nature . doi:10.1038/s41586-020-2313-x

Xu, Z., Shi, L., Wang, Y., Zhang, J., Huang, L., Zhang, C., . . . Wang, F. S. (2020). Pathological findings of COVID-19 associated with acute respiratory distress syndrome. Lancet Respir Med, 8 (4), 420-422. doi:10.1016/S2213-2600(20)30076-X

Yao, Y., Bao, L., Deng, W., Xu, L., Li, F., Lv, Q., . . Qin, C. (2014). An animal model of MERS produced by infection of rhesus macaques with MERS coronavirus. J Infect Dis, 209 (2), 236-242. doi:10.1093/infdis/jit590

Yeh, M. T., Bujaki, E., Dolan, P. T., Smith, M., Wahid, R., Konz, J., . . . Andino, R. (2020). Engineering the Live-Attenuated Polio Vaccine to Prevent Reversion to Virulence. Cell Host Microbe . doi:10.1016/j.chom.2020.04.003

Yin, Y., \& Wunderink, R. G. (2018). MERS, SARS and other coronaviruses as causes of pneumonia. Respirology, 23 (2), 130-137. doi:10.1111/resp.13196

Yu, J., Tostanoski, L. H., Peter, L., Mercado, N. B., McMahan, K., Mahrokhian, S. H., . . . Barouch, D. H. (2020). DNA vaccine protection against SARS-CoV-2 in rhesus macaques. Science. doi:10.1126/science.abc6284

Yu, P., Qi, F., Xu, Y., Li, F., Liu, P., Liu, J., . . Qin, C. (2020). Age-related rhesus macaque models of COVID-19. Animal Model Exp Med, 3 (1), 93-97. doi:10.1002/ame2.12108

Zhou, P., Yang, X. L., Wang, X. G., Hu, B., Zhang, L., Zhang, W., . . Shi, Z. L. (2020). A pneumonia outbreak associated with a new coronavirus of probable bat origin. Nature, 579 (7798), 270-273. doi:10.1038/s41586020-2012-7

Table1: Animal models permissive for SARS-CoV -2 infections.

Table 2: Types of Studies in which different Animal Models can be used

Figure Legends: 
Figure 1: Transmission of SARS-CoV-2 from main reservoir to humans. Bats are the main reservoirs for many other coronaviruses. SARS-CoV-2 may have originated from bats and with the help of unknown intermediate hosts have contributed to human to human transmission.

Figure 2: Utility of small and large animal models of SARS-CoV-2 infection ad pathogenesis . The possible use of animal models in SARS-CoV-2 infection have been described.

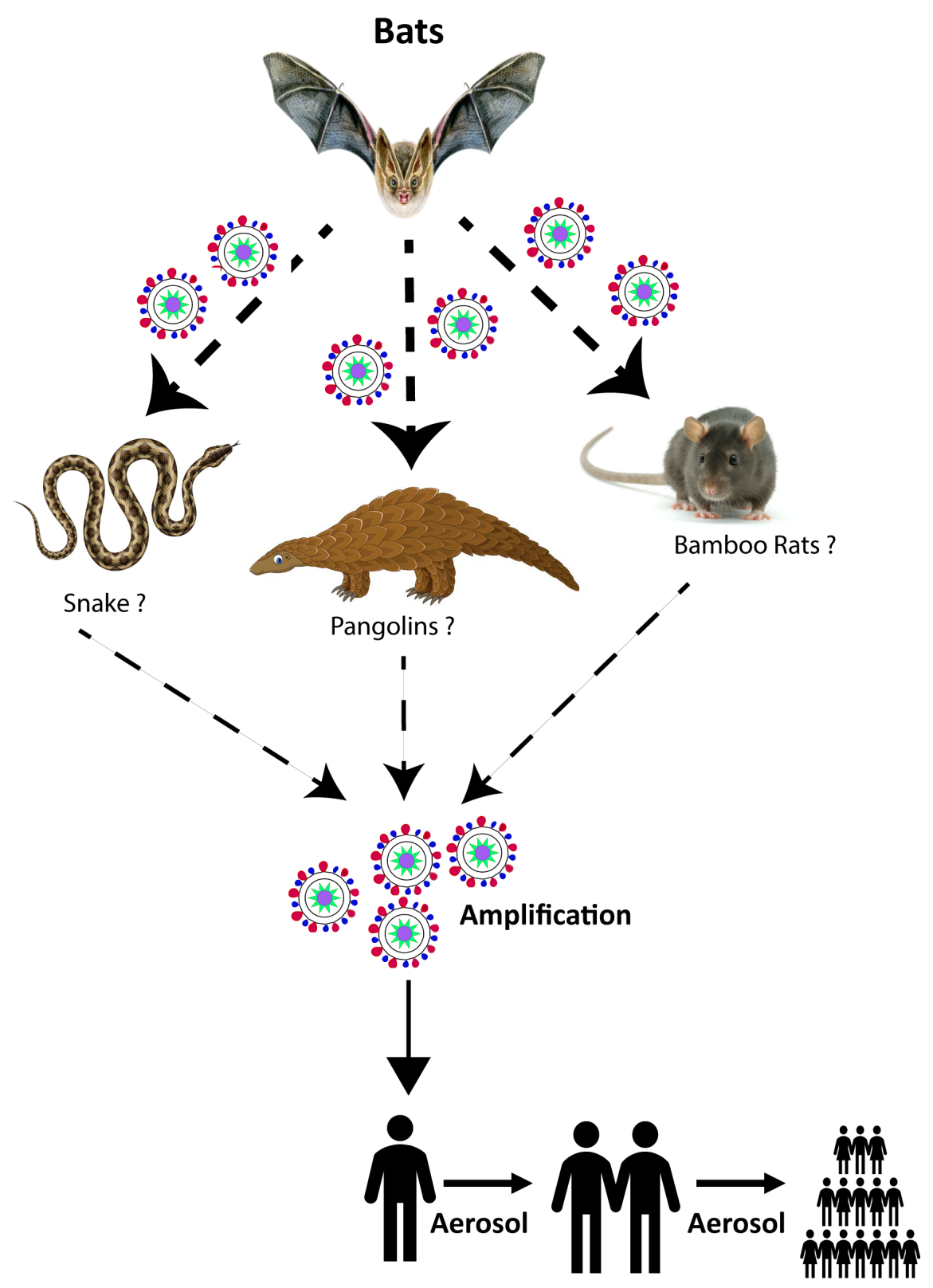




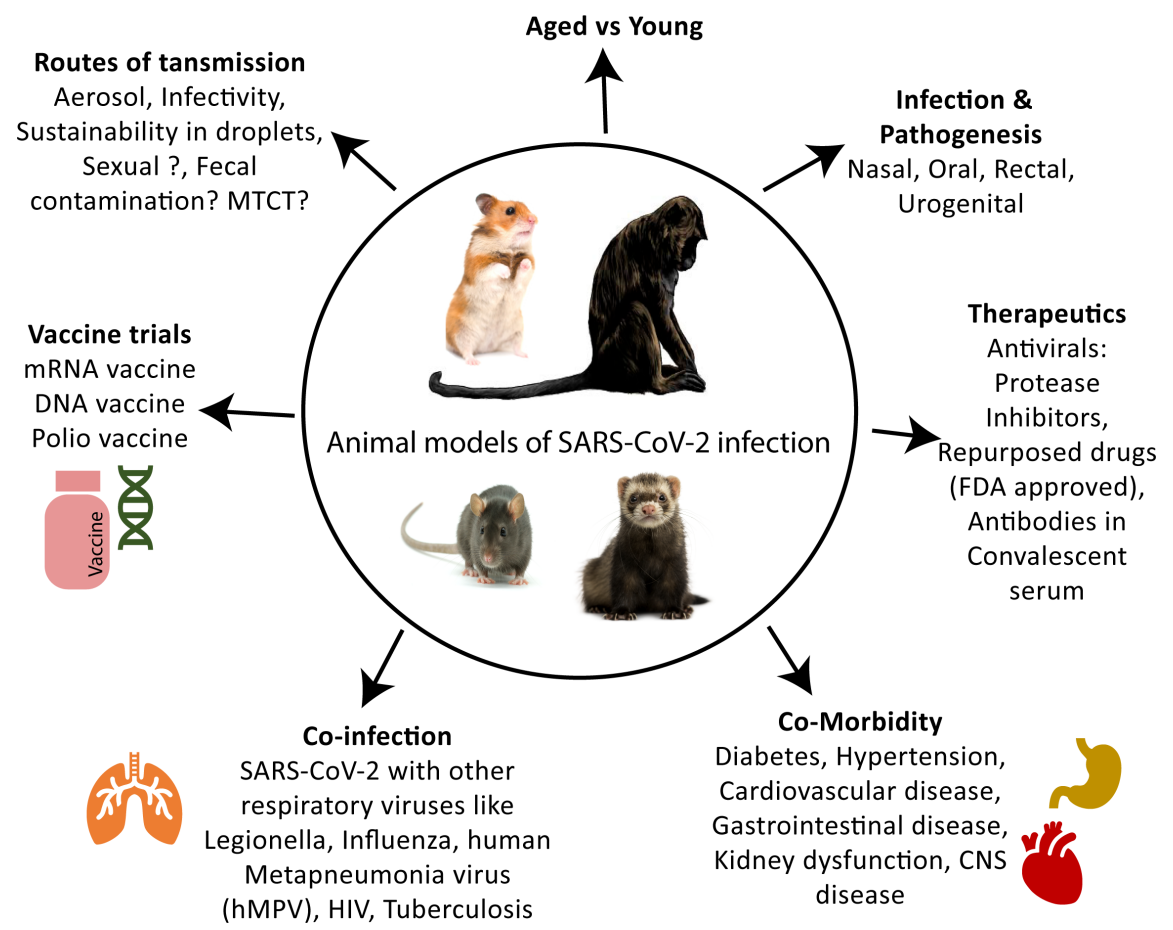

\section{Hosted file}

Table 1. Final.docx available at https://authorea.com/users/335827/articles/461620-animalmodels-for-sars-cov-2-research-systematic-review-of-literature-and-future-directions

Hosted file

Table 2-Final.docx available at https://authorea.com/users/335827/articles/461620-animalmodels-for-sars-cov-2-research-systematic-review-of-literature-and-future-directions 